\title{
La Constitution du 4 novembre 1848 : l'ambition d'une république démocratique, Textes réunis par Jean Bart, Jean-Jacques CLÈRE, Claude COURVOISIER et Michel VERPEAUX
}

Actes du Colloque de Dijon, 10-11 décembre 1998, Dijon, Éditions Universitaires de Dijon, 2000, 464 p., 240 F.

\section{Raymonde Monnier}

\section{(2) OpenEdition Journals}

Édition électronique

URL : https://journals.openedition.org/ahrf/1184

DOl : 10.4000/ahrf.1184

ISSN : 1952-403X

Éditeur :

Armand Colin, Société des études robespierristes

Édition imprimée

Date de publication : 1 décembre 2001

Pagination : 199-201

ISSN : 0003-4436

Référence électronique

Raymonde Monnier, «La Constitution du 4 novembre 1848 : I'ambition d'une république démocratique, Textes réunis par Jean Bart, Jean-Jacques CLĖRE, Claude COURVOISIER et Michel VERPEAUX», Annales historiques de la Révolution française [En ligne], 326 I octobre- décembre 2001, mis en ligne le 10 mars 2008, consulté le 23 avril 2022. URL : http://journals.openedition.org/ahrf/1184 ; DOI : https://doi.org/10.4000/ahrf.1184

Ce document a été généré automatiquement le 23 avril 2022.

Tous droits réservés 


\section{La Constitution du 4 novembre} $1848:$ l'ambition d'une république démocratique, Textes réunis par Jean Bart, Jean-Jacques CLÈRE, Claude COURVOISIER et Michel VERPEAUX

Actes du Colloque de Dijon, 10-11 décembre 1998, Dijon, Éditions

Universitaires de Dijon, 2000, 464 p., 240 F.

\section{Raymonde Monnier}

Ce colloque s'inscrit dans la série de rencontres organisées par les juristes de l'Université de Bourgogne sur les Constitutions de 1791, de 1793 et de l'an III. Bien que consacré à celle de 1848, il intéresse la Révolution dans la mesure où toute une séance est consacrée aux « inspirations » et à l'influence des constitutions révolutionnaires de la fin du XVIIIe siècle, tandis que d'autres communications et les discussions y font aussi largement allusion. Comme le remarque Jean Bart d'entrée de jeu, "l'oeuvre constitutionnelle de 1848 manifeste à la fois l'influence de la tradition révolutionnaire et la peur d'une véritable démocratie sociale ", une peur du peuple que renforcent, à suivre la discussion générale, les tragiques « événements » de juin, mais qui est surtout à mettre au compte d'une prise de conscience du problème social lié aux progrès de l'industrialisation et de la concentration du prolétariat urbain. La forme républicaine, adoptée par le gouvernement provisoire et confirmée par l'Assemblée constituante dès le 4 mai, renvoie inévitablement aux modèles révolutionnaires français et américains, mais pour ce qui est de la Révolution française, plus à la Convention qu'à la Constituante : c'est toute l'ambiguïté de la référence à 1793 à la fin des années 1840, qui renvoie moins à la terreur qu'à la constitution. L'assemblée unique et le suffrage universel (masculin) manifeste le retour sans doute le plus symbolique aux sources 
républicaines et révolutionnaires de 1792-93, même si les procédures ne sont plus exactement les mêmes et que disparaissent les assemblées primaires, si spécifiques de la période révolutionnaire. Retenons aussi cette autre résurgence hautement symbolique, l'abolition de l'esclavage. Si le problème de la chambre unique a suscité de vives discussions, le principe du suffrage universel, adopté pour l'élection de l'Assemblée constituante, n'a pas été remis en question dans l'immédiat. Pour Annie Bléton-Ruget, les effets de sa mise en place sont indissociables de l'organisation de nouvelles modalités de représentation : l'échec d'une solution républicaine en 1830 et les circonstances historiques de l'officialisation du suffrage universel en 1848, en ont fait à la fois un processus de légitimation du nouveau régime et pour les républicains un «opérateur" global, à la fois principe de souveraineté et modalité d'inclusion sociale, d'où l'ambiguïté non élucidée par la discussion des termes de démocratie et de république. Suffrage direct au canton, scrutin de liste par département, bien que le système soit purement représentatif, il témoigne d'une volonté d'intégration de tous les citoyens et de l'influence des idées socialistes, même si, comme le montre bien Armelle Le Bras-Chopard, il s'agit plus d'une "nébuleuse socialiste" que d'un mouvement unifié. Les socialistes s'intéressent moins aux formes de l'État qu'aux moyens d'intégration sociale, mais l'innovation demeure d'avoir introduit le droit au travail, entendu au sens large, dans le débat constitutionnel. C'est un terrain sur lequel la majorité modérée refuse de s'aventurer, et ce nouveau droit, reconnu le 25 février par le gouvernement provisoire, sera enterré pour longtemps. On voit bien dans ce débat, étudié par Françoise Mélonio, comment la référence aux constitutions révolutionnaires et à l'orthodoxie abstraite de l'égalité des droits de 1789 peut masquer chez les libéraux conservateurs une gêne, voire un certain cynisme. Turgot est invoqué à propos par Tocqueville ou Thiers, pour évacuer le malaise relatif à la question ouvrière en se plaçant dans la filiation des Lumières et de la liberté du travail. Mais l'association garde des partisans et le droit au travail est aussi perçu comme le corollaire du suffrage universel et, par un retour à l'idée de contrat social et aux idéaux du XVIII ${ }^{e}$ siècle, comme un problème plus moral et métaphysique que social ou politique. Reste que pour les femmes, enfermées dans le réseau d'incapacités juridiques du Code civil, la situation est pire qu'au XVIII ${ }^{e}$ siècle : Françoise Fortunet montre que pour elles, la reconquête des droits civils est devenue un préalable à leur accession aux droits politiques.

Dans l'étude des travaux de la Commission de Constitution, Jean-Jacques Clère remarque la référence quasi constante aux concepts du droit constitutionnel élaborés sous la Révolution française, et d'autre part la volonté affirmée de se démarquer aussi bien de la tradition française que de l'exemple américain pour faire une œuvre originale. Pour parentes qu'elles soient, les traditions constitutionnelles française et américaine, analysées par Gérard Fritz, présentent des conceptions différentes de la délégation du pouvoir et de la souveraineté : la notion de contrat social, individualiste et juridique en France où l'assemblée des représentants est censée exprimer la volonté générale, est plus prégnante en Amérique, ce dont témoigne le $9^{\mathrm{e}}$ amendement qui veut que l'énumération des droits ne soit pas interprétée « comme annulant ou restreignant d'autres droits conservés par le peuple». Autre divergence, celle de la notion de constitution et de pouvoir constituant en Amérique qui, quoique connue en France, n'est pas appliquée. La grande innovation de la Constitution de 1848 par rapport à la tradition française est une conception nouvelle du pouvoir exécutif, confié non plus à un organe collégial, mais à un président de la République. Malgré la conscience des 
dangers que peut faire courir à la république un chef unique élu au suffrage universel, on n'en organise pas moins un exécutif fort et indépendant du législatif. Les Constituants ont aussi conscience de la spécificité de la révolution de 1848 , plus sociale que politique. S'ils doivent renoncer à une déclaration des droits faute de consensus, le préambule marque bien leur volonté que le régime se distingue non seulement de la monarchie, mais encore ne soit pas une république "quelconque ». Art politique que celui du préambule, comme le démontre avec beaucoup de rigueur Patrice Rolland, celui-ci est, comme la déclaration des droits, «le lieu où s'énoncent les principes fondamentaux du régime, ses buts et la garantie des droits ", et s'inscrit par là dans la tradition révolutionnaire. Reconnue l'antériorité et la supériorité des droits naturels, la garantie ultime de la république comme celle des droits, placés dans la constitution proprement dite, n'est plus entre les mains des législateurs éternels, Dieu ou la Nature immuable, mais dans celle des hommes. Une fois relevées les continuités inévitables, le texte constitutionnel qui fonde l'éphémère deuxième République, a un caractère qui lui est propre : si la République reste fortement marquée par le libéralisme, le régime reste ouvert à une vision progressiste de la société et de la civilisation. Elle reflète la vision originale d'une génération, celle qui a fait en février, comme le dit Lamartine, «d'assez grandes choses pour avoir le droit d'écrire dans le préambule de sa constitution quelques formules nouvelles, quelques principes nouveaux, capables de subir le regard du temps et de la postérité ». 